\section{The protective role of saffron petal extracts on gentamicin- induced nephrotoxicity in rats}

\author{
Arash Omidi, ${ }^{1}$ Zahra Torabi² \\ 1Animal Health Management Department, \\ School of Veterinary Medicine, Shiraz \\ University, Shiraz; ${ }^{2}$ Animal Science \\ Department, Agriculture Faculty, Birjand \\ University, Birjand, Iran
}

\begin{abstract}
Different potentially therapeutic approaches to prevent or attenuate gentamicin sulfate (GM) induced nephrotoxicity have been proposed. The present study was conducted to investigate the effect of the saffron petals extracts (Crocus sativus) (SPE) on male Wistar rats with kidney failure. Rats (40) were randomly assigned into five groups of 8 animals each: i) the control group, that received normal saline $(0.5 \mathrm{~mL} / \mathrm{kg})$; ii) the $\mathrm{GM}$ group, that received GM $(80 \mathrm{mg} / \mathrm{kg})$ by intraperitoneal (i.p.) injection on a daily basis; iii) the $G M+S P E$ group that received the same dose of GM and SPE (40 mg/kg) by i.p. injection on a daily basis; iv) the $G M+2 S P E$ group, that received the same dose of $\mathrm{GM}$ and twofold of SPE $(80 \mathrm{mg} / \mathrm{kg})$ by i.p. injection on a daily basis; whereas v) $2 S P E+G M$ group, that received $80 \mathrm{mg} / \mathrm{kg}$ of SPE a week before initiating the treatment with GM (prevention group). Significant differences were seen in the concentration of glucose, blood urea nitrogen (BUN), and creatinine between treatment groups and control in the male Wistar rats. GM was observed to cause nephrotoxicity, which was evidenced by an elevation of serum BUN and creatinine levels. The biochemical findings of the current study are concordant with those of histopathologic findings. The results of this study indicate that SPE especially in dose of $40 \mathrm{mg} / \mathrm{kg}$ can ameliorate harmful effects of GM on the kidney. The present results may suggest that the SPE have ameliorative effects on kidney failures induced by GM.
\end{abstract}

\section{Introduction}

Damages induced by aminoglycosides in either man or experimental animals, have been mentioned by many researchers.1,2 Aminoglycosides are the most commonly used antibiotics in the world. ${ }^{3}$ Gentamicin sulfate (GM) is an aminoglycoside antibiotic, which is commonly used for the treatment of infections caused by gram-negative bacteria. The most side effects of aminoglycoside treatment are cochlear, vestibular, and renal impairment. 4 Nephrotoxicity induced by GM has been reported in $10-20 \%$ of therapeutic regimes and is the main limitation to therapeutic efficacy of GM. 5 Results obtained from GM studies often extrapolated to other aminoglycosides. The exact mechanism of GM induced nephrotoxicity is not well understood. Iron chelation and oxidative stress have been implicated in the pathophysiology of ototoxicity and acute renal failure induced by GM.3,6 GM has been shown in both in vitro and in vivo studies to enhance the generation of reactive oxygen metabolites. ${ }^{7}$ Saffron (Crocus sativus L.) is one of the most important and valuable herbs of Iran. Saffron is a perennial stemless herb with numerous medical properties used in traditional medicine. Beneficial effects of saffron in the treatment or prevention of kidney disorders have been noted. ${ }^{8}$ Various pharmacological studies have been done on saffron by researchers. Some effects such as anticonvulsants, antihypertensives, antinociceptive and anti-inflammatory, antidepressants, antimicrobial, anticancer and chemopreventive agent, free radical scavenging, and the prevention of cisplatin-induced nephrotoxicity using the stigma of saffron have been mentioned. Farombi and Ekor, ${ }^{9}$ found that curcumin, a natural antioxidant can be a potent protective agent against renal oxidative damage mediated by GM in rats There was a positive linear correlation between the phenolic content and antioxidant capacity of the medicinal herbs. Antioxidants can neutralize free radicals in the environment and prevent the damaging effects of them. The aim of this study was to investigate the effects of SPE against kidney failure induced by GM by evaluating the blood parameters and kidney histopathology characteristics in male Wistar rats.

\section{Materials and Methods}

\section{Animals}

Forty male Wistar rats with mean body weight of $220 \pm 20 \mathrm{~g}$ were individually housed in polypropylene cages in standard rat house conditions $\left(22-25^{\circ} \mathrm{C}\right.$ and $40-50 \%$ humidity on a 12 hour light-dark cycle). All rats were given free access to food (pellet diet, Javaneh, Khorasan Co, Mashhad, Iran) and tap water.

\section{Animal ethics}

This experiment was accomplished under the approval of the state committee on animal ethics, Birjand Medical University, Birjand, Iran. In addition, we used the recommendations of European Council Directive
Correspondence: Arash Omidi, Animal Health Management Department, School of Veterinary Medicine, Shiraz University, Shiraz, Iran.

Tel.: +98.713.6138745 - Fax:+98.713.2286940.

E-mail: aomidi@shirazu.ac.ir

Key words: Gentamicin sulfate; Kidney failures; Saffron petals; Wistar rat.

Acknowledgements: the authors gratefully acknowledge the financial support for this work that was provided by the Vice Chancellor for Research and Saffron Research Group at Birjand University. The Research Council of Shiraz University is also sincerely appreciated. We truly appreciate Dr. Hassanpoorfard and Dr. Zardast for their help and constructive comments.

Conflict of interest: the authors declare no potential conflict of interest.

Received for publication: 31 May 2015

Revision received: 29 July 2015.

Accepted for publication: 29 July 2015 .

This work is licensed under a Creative Commons Attribution NonCommercial 4.0 License (CC BYNC 4.0).

(C) Copyright A.Omidi and Z. Torabi, 2016

Licensee PAGEPress srl, Italy

Veterinary Science Development 2016; 6:6045 doi:10.4081/vsd.2016.6045

(86/609/EC) of November 24, 1986, regarding the standards in the protection of animals used for experimental purposes. All efforts were made to minimize animal suffering and reduce the number of animals used.

\section{Treatment schedule}

The rats were allowed two weeks to adapt to experimental conditions before the start of the experiment. Experiments were done on 40 male Wistar rats divided into five groups of 8 animals each. The experiment was done in two consecutives weeks (Table 1). Intraperitoneal (i.p.) injection has been used for all solutions. SPE injection was done an hour before the GM injection.

\section{Experimental groups}

Control group: healthy rats, that received the normal saline as placebo, $(0.5 \mathrm{ml} / \mathrm{kg})$ daily; GM group: intoxicated rats, that received GM (80 $\mathrm{mg} / \mathrm{kg}$ ) daily; $G M+S P E$ group: rats were treated with $\mathrm{GM}(80 \mathrm{mg} / \mathrm{kg})$ plus SPE (40 $\mathrm{mg} / \mathrm{kg}$ ) daily; $G M+2 S P E$ group: rats were treated with GM $(80 \mathrm{mg} / \mathrm{kg}$ ) plus twofold of SPE (80 $\mathrm{mg} / \mathrm{kg}$ ) daily; $2 S P E+G M$ group: (prevention) rats had experienced with the injection of $80 \mathrm{mg} / \mathrm{kg}$ of SPE during 6 consecutive days, then in 7 th days injection of GM $(80 \mathrm{mg} / \mathrm{kg})$ 
was initiated and lasted in daily manner for a week.

\section{Preparing the petal extract}

The SPE were collected from Birjand city in South Khorasan province, North-east of Iran, during October 2011 (Figure 1). The samples were identified by the Agricultural Faculty of Birjand University, Iran. The voucher number specimen (No. 1766) was deposited in the herbarium of Birjand University, Iran. To prepare the petal extracts, the samples were dried in shadow and then pulverized with a grinder (Hamilton Beach Brand, Canada). Hydroalcoholic extract was prepared by using $50 \mathrm{~g}$ of the dried powder in $1000 \mathrm{~mL}$ of $80 \% \mathrm{v} / \mathrm{v}$ ethanol and shaking for $24 \mathrm{~h}$. Then, the mixture was filtered through No. 1 Whatman filter paper and was oven dried at $40^{\circ} \mathrm{C}$ for $24 \mathrm{~h}$. The final powdered extract was then weighed to calculate the yield. The yield (w/w) of the ethanolic petal extract was $30 \%$.

\section{Biochemical and histopathological analysis}

At 24 hours following administration of the last dose, the animals were anesthetized with ether and blood samples were collected by cardiac puncture. Sera were separated by centrifugation of the samples at $750 \mathrm{~g}$ for $15 \mathrm{~min}$ at room temperature, and were stored at $-21^{\circ} \mathrm{C}$ for further analysis. All biochemical parameters including urea nitrogen (BUN), creatinine and glucose were measured by commercial kits (Pars Azmoon Co., Tehran, Iran). Biochemical analyses were measured using a standard autoanalyser with veterinary software (Cobas-Mira, ABX-Diagnostics, Japan). The serum concentrations of sodium and potassium were measured by the flame photometric method (Flame Photometer, Fater Electronic Rizpardaz ${ }^{\circledR}$, Iran). A urine sample was collected by bladder puncture and creatinine and protein were measured using Jaffe and Biuret methods, respectively. The right kidney was removed and fixed in 10\% formalin buffer at room temperature. After fixing the tissue, it was thoroughly washed under running water and dehydrated in ascending grades of ethyl alcohol, cleared, and embedded in soft paraffin. Tissue sections of about $5 \mu \mathrm{m}$ were obtained, and stained by hematoxylin and eosin (H\&E), and examined under light microscope.

\section{Statistics}

Data were expressed as mean \pm standard error of mean (SEM). The differences among treated groups were analyzed by one-way ANOVA followed by Tukey test. Significance level set at $\mathrm{P}<0.05$.

\section{Results}

Concentrations of glucose, BUN, creatinine, uric acid, sodium and potassium in the serum as well as protein and creatinine in urine of male Wistar rats are shown in the Table 2 . The lower serum levels of glucose were observed in rats of $2 S P E+G M$ group. Serum BUN and creatinine concentrations in $G M+S P E$ group were almost similar to the control group. Serum BUN and creatinine concentrations were sig- nificantly elevated in other groups. Urine protein and ratio of urine protein to urine creatinine (UP/UC) were significantly lower in $G M \pm S P E$ group. Quantitative and qualitative morphological analyses were used to evaluate histologic changes in the kidney sections. Lesions were graded in a single-blind manner using a same scale. The normal structures of glomerulus, proximal and distal tubules were seen in healthy rats of the control group. Necrosis, along with proximal and distal tubules desquamation, was seen in GM group ( $80 \mathrm{mg} / \mathrm{kg}$, daily, i.p.). Some damages in proximal and distal tubular epithelial cells were prevented in $G M+S P E, G M+2 S P E$ and $2 S P E+G M$ groups. In overall, SPE reduced the degree of kidney tissue damages induced by GEN (Figure 2).

\section{Discussion and Conclusions}

Rats that received 2SPE earlier than GM showed lower level of glucose $(\mathrm{P} \leq 0.05)$. Saffron is considered as a source of polyphenols and carotenoids, which have antioxidant ability and capable to reduce blood glucose and inhibition of pancreatic lipase, lipoprotein lipase and glycerophosphate dehydrogenase. ${ }^{10}$

Table 1. Treatment schedule of male Wistar rats exposed to gentamicin sulfate and saffron petal extract $(n=40)$.

\begin{tabular}{lcccc} 
Group/week, mg/kg & FM & First & Second & SPE \\
Control & 0 & 0 & 0 & 0 \\
GM & 0 & 0 & 80 & 0 \\
\hline GM+SPE & 0 & 0 & 80 & 40 \\
GM+2 SPE & 0 & 0 & 80 & 80 \\
\hline 2 SPE+GM & 0 & 80 & 80 & 0 \\
\hline
\end{tabular}

Control group: healthy rats, that received the normal saline as placebo, $(0.5 \mathrm{~mL} / \mathrm{kg})$ daily; GM group: intoxicated rats, that received GM ( 80 $\mathrm{mg} / \mathrm{kg})$ daily; $G M+S P E$ Group: rats were treated with GM $(80 \mathrm{mg} / \mathrm{kg})$ plus SPE $(40 \mathrm{mg} / \mathrm{kg})$ daily; $G M+2 S P E$ group: rats were treated with GM $(80$ $\mathrm{mg} / \mathrm{kg}$ ) plus twofold of SPE ( $80 \mathrm{~mL} / \mathrm{kg}$ ) daily; 2SPE+GM group: (prevention group) rats had experienced with the injection of 80mg $/ \mathrm{kg}$ of SPE during 6 consecutive days, in $7^{\text {th }}$ days injection of GM $(80 \mathrm{mg} / \mathrm{kg})$ was initiated and lasted in daily manner for a week; GM, Gentamicin sulfate; SPE, saffron petal extract.

Table 2. Biochemical analysis of serum levels of glucose, BUN, creatinine, uric acid, electrolytes, and urine creatinine and protein in male Wistar rats $(\mathrm{N}=8$ in each group).

\begin{tabular}{|c|c|c|c|c|c|c|c|c|c|}
\hline Group/parameter & $\begin{array}{l}\text { Glucose, } \\
\mathrm{mmol} / \mathrm{L}\end{array}$ & $\begin{array}{l}\text { BUN, } \\
\mathrm{mmol} / \mathrm{L}\end{array}$ & $\begin{array}{c}\text { Creatinine, } \\
\text { Imol/L }\end{array}$ & $\begin{array}{l}\text { Uric acid, } \\
\text { Imol/L }\end{array}$ & $\begin{array}{c}\mathrm{Na}, \\
\text { xmmol/L }\end{array}$ & $\begin{array}{c}\mathrm{K}, \\
\mathrm{mmol} / \mathrm{L}\end{array}$ & $\begin{array}{l}\text { Urine protein, } \\
\text { mg/dL }\end{array}$ & $\begin{array}{c}\text { Urine creatinine, } \\
\mathrm{mg} / \mathrm{dL}\end{array}$ & UP/UC \\
\hline Control & $9.94 \pm 0.83$ & $12.31 \pm 1.02$ & $57.46 \pm 1.76$ & $172.49 \pm 28.55$ & $64.52 \pm 0.63$ & $1.08 \pm 0.04$ & $155.83 \pm 10.44$ & $131 \pm 31.37$ & 1.18 \\
\hline GM & $7.02 \pm 0.28$ & $27.66 \pm 0.97$ & $111.38 \pm 8.39$ & $184.98 \pm 14.27$ & $63.14 \pm 0.91$ & $1.06 \pm 0.06$ & $133 \pm 15.37$ & $92.1 \pm 31.24$ & 1.44 \\
\hline $\mathrm{GM} \pm \mathrm{SPE}$ & $7.7 \pm 1.17$ & $17.31 \pm 0.76$ & $81.05 \pm 7.95$ & $175.46 \pm 14.87$ & $63 \pm 0.79$ & $1.17 \pm 0.04$ & $52.5 \pm 7.28$ & $89 \pm 37.58$ & 0.58 \\
\hline $\mathrm{GM} \pm 2 \mathrm{SPE}$ & $9.91 \pm 1.17$ & $22.03 \pm 0.99$ & $101.66 \pm 0.88$ & $196.87 \pm 24.38$ & $66.24 \pm 0.43$ & $1.14 \pm 0.05$ & $196.28 \pm 65.47$ & $95.14 \pm 16.09$ & 2.06 \\
\hline $2 \mathrm{SPE} \pm \mathrm{GM}$ & $6.52 \pm 0.54$ & $19.45 \pm 2.08$ & $91.05 \pm 7.95$ & $200.44 \pm 16.65$ & $64.59 \pm 0.78$ & $1.05 \pm 0.06$ & $216.62 \pm 39.96$ & $107.78 \pm 19.27$ & 2 \\
\hline Pvalue & $\leq 0.05$ & $\leq 0.05$ & $\leq 0.05$ & NS & NS & NS & $\leq 0.05$ & NS & $\leq 0.05$ \\
\hline
\end{tabular}

Control group: healthy rats, that received the normal saline as placebo, $(0.5 \mathrm{ml} / \mathrm{kg}$ ) daily; GM group: intoxicated rats, that received GM (80 $\mathrm{mg} / \mathrm{kg})$ daily; GM+SPE Group: rats were treated with GM ( $80 \mathrm{mg} / \mathrm{kg})$ plus SPE $(40 \mathrm{mg} / \mathrm{kg})$ daily; $G M+2 S P E$ group: rats were treated with GM $(80 \mathrm{mg} / \mathrm{kg})$ plus twofold of SPE ( $80 \mathrm{ml} / \mathrm{kg})$ daily; $2 S P E+G M$ group: (prevention group) rats had experienced with the injection of $80 \mathrm{mg} / \mathrm{kg}$ of SPE during 6 consecutive days, in 7 th days injection of GM $(80 \mathrm{mg} / \mathrm{kg})$ was initiated and lasted in daily manner for a week; GM, Gentamicin sulfate; SPE, saffron petal extract; BUN, blood urea nitrogen; UP, urine protein; UC, urine creatinine. 
A similar mechanism may be raised about SPE that administered prior that GM injection. Many studies have shown that the SPE have a large variety of flavonoid compounds, glycosides and anthocyanins. Iranshahi and colleagues, 11 assume that most hepatoprotective effect of SPE is due to flavonoide and anthocyanins (phenolic compounds). Flavonoids can inhibit the fatty acids enzymatic peroxidation and also have free radical scavenging property. In the present study, GM caused a marked nephrotoxicity as evidenced by significant increases in serum BUN (225\%) and creatinine (194\%). Increased BUN and creatinine levels suggest impaired kidney function. The results demonstrated amelioration of GMinduced renal toxicity in rats by SPE. Injection of SPE and 2SPE was found to lower the serum BUN by 38 and $20 \%$ in rats that received GM respectively. In rats of $2 S P E+G M$ group, BUN decreased till 30\%. SPE and 2SPE injection was found to lower the serum creatinine by 27 and $9 \%$ in rats that received $\mathrm{GM}$ respectively. In rats of $2 S P E+G M$ group, creatinine decreased till 19\%. Urine protein and UP/UC were significantly lowered in $G M+S P E$ group. Generally, UP/UC test gives similar information to the 24hour urine protein determination from a single collection. This ratio is sensitive to significant protein loss, with a value of greater than 1.0 prompting immediate investigation. ${ }^{12}$

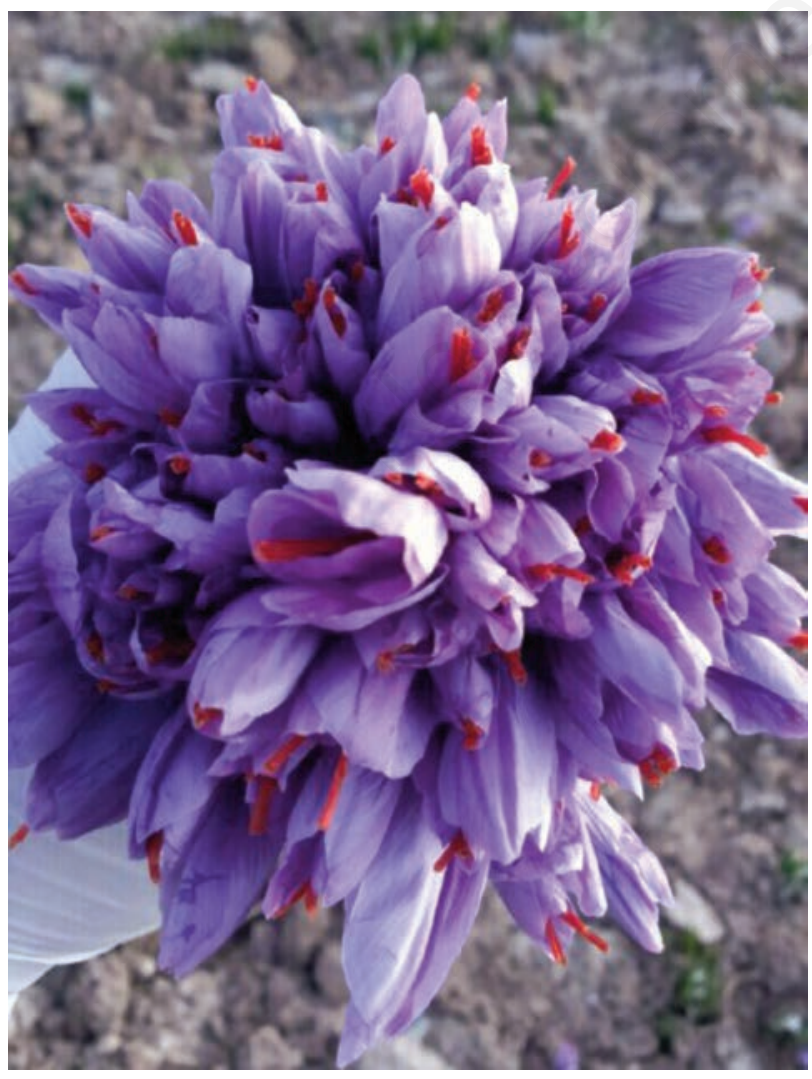

Figure 1. The purple saffron petal is used in the experiment.
Because the sample was obtained of urine at the end of the experiment, it is not known how much this finding is worth. In the histopathology of renal tissues, normal structure of glomerulus, proximal and distal tubules, in shape, number and size were seen. Necrosis, along with proximal and distal tubules desquamation, was seen by administration of GM, (80 $\mathrm{mg} / \mathrm{kg} \mathrm{bw})$. Damages in proximal and distal tubules were prevented in $G M+S P E$ and $G M+2 S P E$ groups more than $2 S P E+G M$ group. Morphological changes in the kidney along with biochemical findings showed that administration of SPE reduced the GM nephrotoxicity. Many recent studies suggest role of reactive oxygen species (ROS) generation in the kidney in GM nephrotoxicity. Polat and colleagues, ${ }^{13}$ used aminoguanidine as an effective antioxidant against GM nephrotoxicity in an in vivo rat model. Aminoguanidine significantly decreased BUN level. They propose that aminoguanidine acts in the kidney as a potent scavenger of free radicals to prevent the toxic effects of GM. In another study by Al-Majed,14 curative role of arabic gum which has been widely used by eastern folk medicine practitioners in treatment of renal failure was evaluated. Arabic gum protected the rats from GM nephrotoxicity ( $80 \mathrm{mg} / \mathrm{kg}$, daily, i.p.) possibly by inhibition of the production of oxygen free radicals. Caffeic acid phenethyl ester (CAPE) significantly decreased serum BUN and creatinine levels in GM nephrotoxicity. Probably, CAPE acts in the kidney as a potent scavenger of free radicals to prevent the toxic effects of GM both at the biochemical and histological level. ${ }^{15}$ Administration of vitamin $\mathrm{C}$ in equines could have a protective effect against GM nephrotoxicity.16 Protective effects of vitamin E and probucol against GM nephrotoxicity in rats were evaluated by Abdel-Naim and colleagues. ${ }^{17}$ In the mentioned study, vitamin $\mathrm{E}$ pretreatment significantly lowered the elevated serum BUN and creatinine levels, probably due to their antioxidant activity. Saffron petals (SP) are a rich source of flavonoids, which can be potentially used as an antioxidant compound in pharmaceutical research. ${ }^{18}$

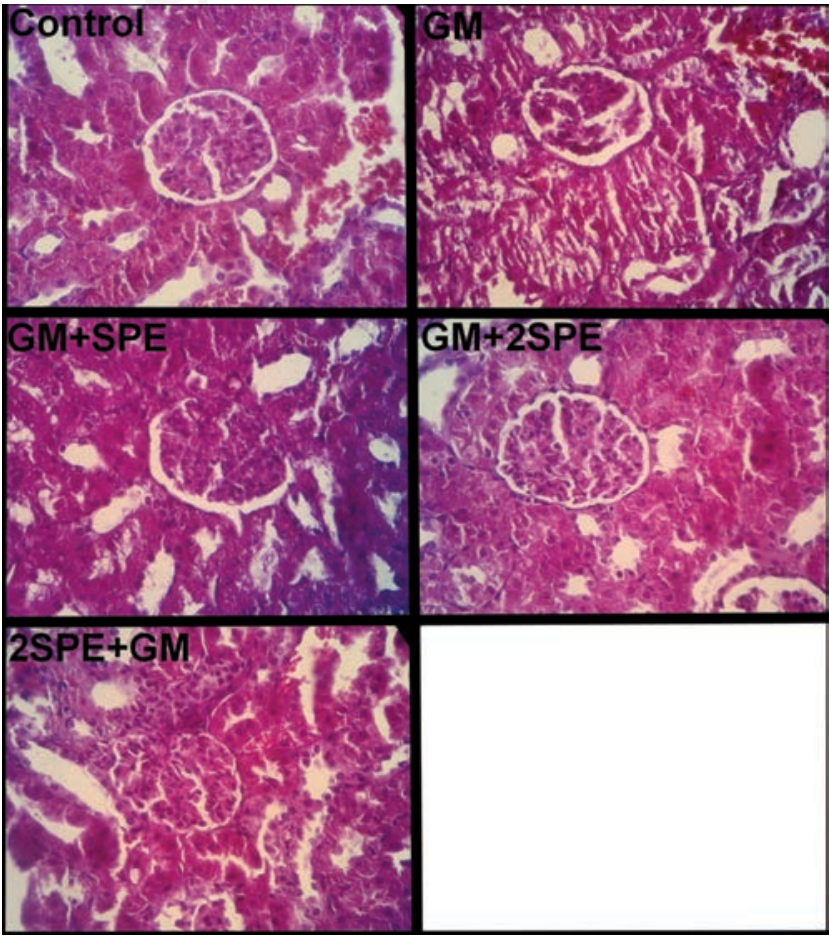

Figure 2. Photomicrographs of different experimental groups showing the histopathology of renal tissues. Control: normal structure of glomerulus, proximal and distal tubules, in shape, number and size are seen. GM: necroses along with proximal and distal tubules desquamation were seen by administration of gentamicin sulfate $(\mathrm{GM}),(80 \mathrm{mg} / \mathrm{kg} \mathrm{bw}) . G M+S P E$ : with coadministration of gentamicin and low dose of saffron petal extract (SPE), $(40 \mathrm{mg} / \mathrm{kg} \mathrm{bw})$ damages in proximal and distal tubular epithelial cells are obviously prevented. $G M+2 S P E$ : damages in proximal and distal tubes are prevented in lesser extent compared with $G M+S P E$ group. 2SPE+ GM: damage of proximal and distal tubes is prevented in some degrees, but lesser than $G M+S P E$ and $G M+2 S P E$ groups. 
Flavonoids are powerful antioxidants and prevent DNA damages. SP are one of the easily accessible sources of natural antioxidants and several amounts of them are obtained during the saffron processing. The protective effect of SPE in prevention of acetaminophen induced liver and kidney damages in male Wistar rats was shown by Omidi and colleagues. ${ }^{19,20}$ In addition, in a preliminary study on the effects of SPE in lambs, some antioxidant activities of SPE in sheep was noticed by Omidi and colleagues. ${ }^{21}$ Ardalan and colleagues ${ }^{22}$ found that SPE has a considerable effect on scavenging free radicals. The concentration of $500 \mathrm{ppm}$ of SPE is equal to a synthetic antioxidant (TBHQ) at the level of $100 \mathrm{ppm}$ in vitro. The main overall finding from this study was that SPE especially in $40 \mathrm{mg} / \mathrm{kg}$ may be useful for its antioxidant benefits and may possess ameliorative effects on kidney failures induced by GM. The findings of the present study will, we hope, serve as a valuable basis for future research and clinical trials in use of SPE as effective preventive agent in nephrotoxicity.

\section{References}

1. Lieberthal W, Nigam SK. Acute renal failure II. Experimental models of acute renal failure: imperfect but indispensable. Am J Physiol Renal Physiol 2000;278:F1-F12.

2. McKinney W, Yonovitz A, Smolensky MH. Circadian variation of gentamicin toxicity in rats. Laryngoscope 2015;125:E252-6.

3. Schacht J. Aminoglycoside ototoxicity: prevention in sight? Otolaryngol Head Neck Surg 1998;118:674-7.

4. Nakashima T, Teranishi M, Hibi T, et al. Vestibular and cochlear toxicity of aminoglycosides-a review. Acta Otolaryngol 2000;120:904-11.

5. Quiros Y, Vicente-Vicente L, Morales AI, et al. An integrative overview on the mechanisms underlying the renal tubular cytotoxicity of gentamicin. Toxicol Sci 2011;119:245-56.

6. Randjelovic P, Veljkovic S, Stojiljkovic N, et al. Protective effect of selenium on gentamicin-induced oxidative stress and nephrotoxicity in rats. Drug Chem Toxicol 2012;35:141-8.

7. Baliga R, Ueda N, Walker PD, Shah SV. Oxidant mechanisms in toxic acute renal failure. Am J Kidney Dis 1997;29:465-77.

8. Ajami M, Eghtesadi S, Pazoki-Toroudi H, et al. Effect of crocus sativus on gentamicin induced nephrotoxicity. Biol Res 2010;43: 83-90.

9. Farombi E0, Ekor M. Curcumin attenuates gentamicin-induced renal oxidative damage in rats. Food Chem Toxicol 2006;44: 1443-8.

10. Muosa F, Kadhim AR, Askar SJ, Yousif EH. Evaluation of the toxic effect of ethanolic extract of saffron in male mice after subchronic exposure. Donnish J Pharm Pharmacol 2015;1:1-7.

11. Iranshahi M, Khoshangosht M, Mohammadkhani Z, Karimi G. Protective effects of aqueous and ethanolic extracts of saffron stigma and petal on liver toxicity induced by carbon tetrachloride in mice. Pharmacology 2011;1:203-12.

12. Waldrop JE. Urinary electrolytes, solutes, and osmolality. Vet Clin North Am Small Anim Pract 2008;38:503-12.

13. Polat A, Parlakpinar H, Tasdemir S, et al. Protective role of aminoguanidine on gentamicin-induced acute renal failure in rats. Acta Histochem 2006;108:365-71.

14. Al-Majed AA, Mostafa AM, Al-Rikabi AC, AlShabanah 0A. Protective effects of oral arabic gum administration on gentamicininduced nephrotoxicity in rats. Pharmacol Res 2002;46:445-51.

15. Parlakpinar H, Tasdemir S, Polat A, et al.
Protective role of caffeic acid phenethyl ester (cape) on gentamicin-induced acute renal toxicity in rats. Toxicology 2005;207:169-77.

16. El-Ashker M, Abdelhamid F, Risha E, et al. Vitamin C ameliorates gentamicininduced acute kidney injury in equines: an experimental study. J Equine Vet Sc 2015;35:238-43.

17. Abdel-Naim AB, Abdel-Wahab MH, Attia FF. Protective effects of vitamin E and probucol against gentamicin-induced nephrotoxicity in rats. Pharmacol Res 1999;40:183-7.

18. Omidi A, Torabi Z, Hassanpoorfard M, Zardast M. Evaluation of protective effect of hydroalcoholic extract of Crocus sativus petals on preventing of gentamicin induced peliosis hepatis and hepatic telangiectasis in rats: short communication. J Birjand Uni Med Sci 2013;19:45562.

19. Omidi A, Riahinia N, Torbati MBM, Behdani MA. Hepatoprotective effect of Crocus sativus (saffron) petals extract against acetaminophen toxicity in male Wistar rats. Avicenna J Phytomed 2014;4:330.

20. Omidi A, Riahinia N, Torbati MBM, Behdani MA. Evaluation of protective effect of hydroalcoholic extract of saffron petals in prevention of acetaminopheninduced renal damages in rats. Vet Sci Develop 2015;5:68-71.

21. Omidi A, Rahdari S, Fard MH. A preliminary study on antioxidant activities of saffron petal extracts in lambs. Vet Sci Develop 2014;4:5161-4.

22. Ardalan T, Ardalan P, Heravi MM. Kinetic study of free radicals scavenging by saffron petal extracts. J Chem Health Risks 2012;2:29-36. 